\title{
The Role of YouTube in the Digitalization of TV: A Case Study of Novel Value Co-creation Practices at United Screens
}

\author{
Evelina Griborn \\ Umeå University \\ evelina.griborn@gmail.com
}

\author{
Daniel Nylén \\ Umeå University \\ daniel.nylen@umu.se
}

\begin{abstract}
Research has shown how incumbent firms in contentbased industries (e.g. music, news and photography) were radically affected by digitalization as powerful digital platforms emerged as new loci of innovation. While scholars have suggested that digital technology calls for novel organizing logics and value creation processes, there is a need for further knowledge of what characterizes them, and how they emerge in practice. In addressing this gap we studied United Screens, a firm that capitalizes on the digitalization of video contents by managing major YouTubers and connecting them with advertisers. The study shows how United Screens leverages the layered modularity of digital product architectures for new constellationbased modes of value co-creation. Overall, the paper contributes to research on digital innovation by shedding light on how a novel actor category champions content-driven value creation, an underexplored aspect of digital platform ecosystems.
\end{abstract}

\section{Introduction}

Digitalization is associated with major shifts in the way firms organize and do business [35, 28]. During the past decade, the media industry has experienced significant disruptions that challenge traditional ways of structuring business, thereby paving the way for new actors entering the field. Historically, broadcast television (TV) was the given channel for video-based content distribution. However, this dominant position is currently eroding as viewers are increasingly turning to video-sharing services (e.g. Vimeo, Dailymotion, and YouTube) [4], triggering a shift in advertising spending from broadcast TV to digital platforms [32].

Firms that engage in advertising efforts on videosharing websites increasingly seek to partner with individual content creators in order to tap into their audiences. A new actor category has emerged to orchestrate such ventures - Multi-channel networks $(M C N s)$ [32] - which acts as an intermediary between advertisers and content creators. The emergence of MCNs is enabled by the unique architecture of digital products, which offers new ways of producing, distributing, consuming, and interacting with contents [35]. While analog contents are associated with tightly coupled services, networks, and devices, digitalization loosens these couplings, allowing for far greater flexibility, enabling collaborative and distributed value co-creation practices together with shifts in the dispersion of control across heterogeneous actors [35]. In this paper, we address an understudied aspect of this transformation: how emergent actor categories organize to co-create value based on digital contents. To do so we draw on an exploration of how MCNs structure their businesses, specifically asking: How does a MCN organize for value-creation in a digitalized environment?

To answer this question, we conducted a qualitative case study at Swedish MCN United Screens. Our findings explore the key components of United Screens' value propositions to advertisers and content creators, while illustrating how the firm's collaborative projects are configured. We also discover the organizational structures that United Screens has put in place to organize work internally, while revealing tensions between advertisers and content creators concerning control over content production, and how these tensions are resolved. In this way, the study shows how United Screens leverage the loosely coupled layers of digital product architectures in ways that enable them to effectively compete with incumbent broadcast TV firms. We contribute by generating rich insights into a relatively neglected aspect of digital platform ecosystems - the emergence of new modes of content-driven value co-creation practices championed by a novel actor category.

The remainder of the paper is organized as follows. First related research, the research context and methodology are presented. Next, we present the findings, and discuss their implications. Finally, we 
elaborate on the limitations of the present study, while suggesting promising avenues to pursue for future research.

\section{Digital product architectures and value co-creation}

Information Systems research has paid significant attention to how firms organize in relation to the acquisition, deployment and management of Information Technology [23]. In the 1980s and 1990s, scholarly debates revolved around the virtues associated with centralized, decentralized, and federal modes of administration. However, such concepts seem inadequate when considering current organizational implications of the distinct aspects of digital product architectures [35]. Digital technology is currently associated with significant changes in the outbound dimensions of the firm-level value creation process [21]. As distribution, sales, and marketing is increasingly conducted through digital channels, contents and services become interconnected with digital platforms and associated business ecosystems $[29,19]$.

To investigate MCNs as a phenomenon, we draw on Yoo et al.'s [35] conceptualization of the distinct aspects of digital product architectures. Allowing for greater flexibility than analog products, this architecture encompasses four loosely coupled layers: devices, networks, services and contents [35]. Firstly, the device layer is separated into two elements: physical components (such as computer hardware) and logical capabilities of (for example) operating systems. A key property of the digital product architecture is the role of logical capabilities in connecting physical features of devices to the other three layers. Secondly, the network layer enables physical transport via cables and transmitters, and logical transport via network standards such as the TCP/IP protocol. Thirdly, the service layer - more visible to end users encompasses functionality that enables creation and consumption of digital content. Finally, the contents layer refers to digital data and information, for example in the form of text, image or video [35].

Digitalization loosens the couplings of the four layers, enabling a far more flexible approach to the production, distribution, and consumption of video contents [35]. For example, traditional broadcast TV required: (1) specific services and channels provided by media corporations; (2) distribution by airwaves or cable, enabled by transmitters and receivers converting radio signals into humanly perceptible audio and video signals or cables made of appropriate physical materials, for example copper or optical fibers; and (3) physical devices, i.e. television sets, with tightly coupled logical elements of the four layers. In contrast, video content published on digital video-sharing platforms such as YouTube is consumed through diverse services including websites, applications and extensions, and distributed via various online networks utilizing the Internet as a standardized and open infrastructure [14].

Analog product architectures require users to engage with a certain service, network, or device. In contrast, users who seek to produce, distribute, and consume digital content have multiple choices associated with each layer. In this way, the loosely coupled layers of digital products also allows form and function to be separated and readily recombined across various services and devices [34]. Since bindings across the four layers are only temporary - or procrastinated during consumption [36], value is accordingly generated in use [31]. Thus, there are no clear demarcations between design and use of digital products - they are continuously in the making - codesigned by multiple actors [7].

As digital product architectures allow external actors to expand the functionality of products, control over digital products is distributed, and value creation occurs as heterogeneous actors recombine resources across the four layers [35, 12]. Here, the locus of control is shifting from the single firm to virtually any end-user [20]. In this way, low-cost and easy-to-use digital technologies empower the individual user and facilitate new practices of user-driven dynamic cocreation of contents and value $[12,16]$. Consequently, digital technology control points increasingly reside outside of organizational boundaries [19], whereby organizations seek to harness opportunities to interact with consumers in novel ways by for example stimulating the creation of user-generated contents in their services $[10,27]$. In such efforts, however, a key organizational challenge lies in balancing conflicting requirements for control and openness to external contributions [9].

In contrast to the relatively fixed and static value chains of the industrial era, value creation in the digital age increasingly occurs across business ecosystems $[19,25]$ where multiple actors with complementary resources form temporary constellations in which value is co-created [18, 19]. Here, firms have to formulate and test compelling value propositions - invitations to engage in the co-creation of value - directed at diverse actors $[16,31]$. In this way, business ecosystems are technological environments founded on symbiotic relationships that are continuously reshaped to create reciprocal value for their members, in which actors simultaneously compete and cooperate [25]. Powerful 
platforms have become the loci of innovation in such ecosystems of the digital domain [29].

Digital platforms facilitate multi-sided markets as they "enable direct interactions between two or more distinct sides." [13, p. 163]. A key strength of platforms is that they both offer foundations that remain robust over time (albeit increasingly brief time), and facilitate variability $[8,1]$. In this way, novelty can be created without the development of entirely new systems. While IS research has generated valuable insights on digital platform ecosystems, it has thus far predominantly focused on how so called boundary resources (i.e. SDKs and APIs) enable distributed innovation as third parties develop apps [9, 29, 5]. Furthermore, as pointed out by Selander, et al. [25], this research also tends to analyze platform owners as focal units. This is unfortunate, since a major trend associated with the proliferation of digital platforms is the emergence of new actor categories. For example, as explored by Vaast et al. [30, p. 1070], technology bloggers have come to play important roles in traditional fields having "gained the attention of established actors such as technology firms and journalists". Based on the insight that widespread use of new media is changing the relative positions of established and new actors, they conclude that such media provide vast opportunities for organizations as well as individuals to participate in public and private discourses by diminishing the technological barriers to access [30].

Scholars have highlighted the urgency of facilitating novel organizing logics that can guide the management of increasingly heterogeneous and distributed ways of co-creating value with digital technologies, and support firms in "consider[ing] how to distribute organizational control in a new way and how to cope with the increased heterogeneity of knowledge resources" [35, p. 732]. However, research has yet to generate richer empirical and theoretical understandings about how these distinct aspects of digital technology are enacted in value co-creation processes. In addressing the aforementioned gaps, we draw on an empirical investigation of how new organizing logics and value co-creation processes emerge in practice through a study of United Screens, a born-digital organization.

\section{Research method}

In order to generate an understanding of how United Screens and its partners organize to co-create value we adopt a qualitative case study approach [24, 33]. We chose this approach due to its strengths in uncovering the motivations, experiences and perceptions of respondents [2], while enhancing richness, depth and nuance [22].

\subsection{Research context}

The matching of editorial and commercial contents in broadcast TV has become increasingly optimized. Still broadcast TV networks' advertising business model has essentially remained the same for decades: Firms contract advertising agencies to produce a TV commercial promoting their brand or product, and purchase airtime from a TV-broadcasting network. Communications processes associated with broadcast TV advertising are typically linear, and in this way Broadcast TV is characterized by undirected communications that "address the entire audience base at large without targeting a specific party and without regard for past interactions contexts" [10, p. 89]. However, Broadcast TV is rapidly losing ground to new forms of directed digital video content distribution that are highly interactive, targeting specific consumer groups $[4,10,3]$.

In 2015, smartphones, tablets and laptops were reportedly used for $53 \%$ of all video consumption by people aged 16-34 years [6]. YouTube is today one of the world's most frequently visited websites. With 15 billion daily views, it attracts one billion unique visitors each month, thereby reaching $40 \%$ of the online population [32]. Game commentator PewDiePie runs the most heavily subscribed channel on the platform, and as of April 2016, he had more than 43 million subscribers, and a total of more than 11 billion views [26]. Following this turn to online video contents, YouTube has become a major platform through which diverse actors seek to create and appropriate value.

In the late $00 \mathrm{~s}$, YouTubers began to generate considerable revenue from advertisements. Consequently, there was a rapid emergence of "entities that affiliate with multiple YouTube channels, often to offer content creators assistance in areas including product, programming, funding, cross-promotion, partner management, digital rights management, monetization/sales, and/or audience development" [11]. These organizations are typically referred to as multi-channel networks (MCNs). MCNs help content creators to monetize their video contents in exchange for a percentage of the channel's ad revenue. It is important to note that $\mathrm{MCNs}$ are separate from YouTube and Google: they merely exploit the YouTube platform's capabilities [15]. Aggregating the curated video contents, market-leading MCNs such as Maker Studios and Fullscreen attract billions of views each month [32]. 
Established in Sweden in 2013, United Screens is one of the largest MCNs that target a Scandinavian audience. Partnering with around 450 content creators, United Screens hosts several influential profiles. By supporting their partners and connecting them with advertisers, United Screens is an illustrative example of a firm that was born digital, and primarily builds its business on evolving digital platforms and networks. Thus, a detailed examination of how United Screens and its partners organize to create value seems to offer an ideal opportunity to explore the emergence and business logic of MCNs, phenomena that have received little research attention to date.

\subsection{Data collection and analysis}

Our main data sources are semi-structured interviews with United Screens employees. Firstly, we interviewed partner managers who are responsible for helping YouTubers with everything from choosing video thumbnails and interpreting analytics to establishing and developing collaborations with advertisers. We also interviewed sales personnel, who are responsible for managing branded content and commercial exposure from the customers' perspective, and two YouTubers. Most of the interviews were conducted at United Screens' premises. The roles of the respondents from United Screens and content genres of the YouTubers are summarized in Table 1.

Table 1. Respondent overview

\begin{tabular}{|l|l|}
\hline Respondent & United Screens employees (roles) \\
\hline A & Sales \\
\hline B & Sales \\
\hline C & Sales \\
\hline D & Partner management \\
\hline E & Partner management \\
\hline F & Partner management \\
\hline & YouTubers (content genres) \\
\hline G & Social experiments \\
\hline H & Comedy \\
\hline
\end{tabular}

Informed by the aim of the study, the selection of respondents was consistently purposive, i.e. focusing on their potential to contribute to a "detailed exploration and understanding of the central themes and puzzles which the researcher wishes to study" [22, p. 78]. Following our semi-structured approach, all the interviews were guided by a set of questions covering fundamental themes, thus enabling both a certain level of data consistency and flexibility [2], allowing us to probe relevant, interesting, and sometimes unanticipated topics as they surfaced [22]. All interviews were audio-recorded and subsequently transcribed. Names of all respondents were anonymized to protect integrity.

In seeking to extract meaning from the raw material, our data analysis efforts evolved throughout three cycles of coding [2]. The first cycle involved initial open coding, focused on identifying concentrated characteristics and meaning-bearing units [17]. In the second cycle, we conducted selective coding, focusing on sorting and prioritizing codes and generating aggregated categories. This exercise produced three categories: value propositions, organizational form, and dispersion of control. Finally, theoretical coding was applied to distinguish relationships between the categories of codes. These analytical procedures enabled the identification of similarities and differences in the data, and interpretation of the results on multiple levels of abstraction [17].

\section{Findings}

This section presents the empirical findings of the underlying research (described in the previous section), regarding three distinct but interrelated themes associated with value co-creation.

\subsection{Value propositions}

United Screens acts as a link between content creators who produce and publish digital video clips on YouTube and other social media platforms, and firms that seek to target certain crowds in their marketing efforts. Thereby, they articulate value propositions to both of these two types of actors. Content creators go by many names - e.g. YouTubers, influencers, or channel owners. Here, we mainly refer to these actors as content creators and partners (depending on the context), while we refer to United Screens' clients who seek to market their brands or products as either customers or advertisers. In acting as a mediator between the two groups, United Screens helps its customers to gain access to followers of influential content creators, while helping content creators to develop, grow, optimize, and capture value from their channels.

There are essentially two ways in which United Screens help advertisers to market their brand or product via YouTube. First, through pre-rolls showing 
promotional messages before a clip begins to play. It is important to highlight that YouTube has created algorithms that seek to match pre-rolls with appropriate clips. However, these algorithms have limitations, and the matching between products or brands promoted in the pre-rolls is sometimes far from ideal. In an extreme example recalled by Respondent $\mathrm{B}$, a major airline company had a pre-roll commercial to a video clip that showed a plane crash. Against this backdrop, a key component of United Screens' value proposition to advertisers is its ability to ensure that such unfortunate mismatches are avoided by matching advertisers with the most appropriate partners. Respondent A explains:

You can purchase exposure directly from YouTube, but then you buy from all of YouTube and YouTube has everything, which means that you will find a lot of weird stuff. I mean you can find disgusting food that has been tagged with food [...] If you go through a premium network, then your brand is safe: You know which channels you can end up on and, from there you can choose specific channels just like when you go to TV4 [a Swedish broadcasting network] and purchase exposure during Idol [the Swedish version of Pop Idol/American Idol].

The second way that United Screens help advertisers to market their brand or product via YouTube is through branded content. Here, United Screens contract a content creator that will expose the advertiser's product or brand in the actual video clip. Branded content collaborations require advertisers to collaborate actively with content creators. Accordingly, a key component of United Screens' value propositions to both advertisers and content creators is acting as an intermediary in the initiation and management of such collaborations.

Marketing efforts on YouTube have significant advantages over broadcast TV advertising, as streaming media enable marketing efforts that target more specific audiences. In fact, the vast quantities of analytic data generated by YouTube include various forms of viewer demographics, thus allowing advertising messages to be fine-tuned and targeted towards highly specific crowds:

In contrast to [broadcast] television, where you have like, your spot [...] you have no idea who's watching. On YouTube, I mean, we can direct everything towards registered users, so we know exactly where they live, how old they are, their gender, and everything, which enables you to really aim your campaigns at the specific target you're after. (Respondent B)

If I am to sell a fishing rod, and there is this channel talking about this rod or has - let's say I have commercials about this rod, then only people interested in fishing will see it. (Respondent E)
When collaborating with United Screens in using YouTube for marketing efforts, firms can also follow the impact of their efforts in new ways as they can immediately see comments, numbers of likes and other kinds of reactions. This direct feedback, along with analytics covering viewer habits and demographics, enables advertisers to readily assess what they actually pay for when buying online video exposure. Accordingly, another key component of United Screens' value proposition to advertisers is the capture and interpretation of such data.

Furthermore, since YouTube productions are both cheaper and easier to produce than broadcast television commercials, firms do not have to stick with a single way of advertising their brand;

If you broadcast to four million Swedes, and have this message like "Go buy Gevalia coffee," then you have to make that message appeal to as many of them as possible. Otherwise, it will be money wasted, right? With streaming media, you don't need to limit yourself to one single message; you can have 10 different messages in different channels, and they don't have to overlap. (Respondent E)

Nearly all of United Screens' 450 partners use prerolls, and about a quarter of them also engage in branded content collaborations. United Screens' value proposition to content creators contains several components, including idea generation, content production and studio facilities, channel development, audience growth, audio and visual rights management, administrative support, and training services. In this way, United Screens helps its partners to increase their incomes by optimizing their channels, in exchange for a portion of the advertising revenue generated.

The content creators included in our study confirm the benefits of working with a MCN: a key advantage being avoidance of chasing collaboration opportunities, which is time-consuming. By letting United Screens handle incoming requests from firms that want to initiate affiliation, partners can focus on creating content and interacting with their followers:

They solve it and spare us the hassle, like invoicing and shit, that's just gone. They take care of it and we don't have to think as much, we can just focus on being creative and yeah, they get paid for doing it... of course. (Respondent G)

Most of the time United Screens contact me when they have a brand that fits my target group and my audience, and maybe wants to do comedy and be a bit funny. Then they reach out to me and say "We have this firm, they want do this", and then I decide if I want to go with it. I get a brief saying do this or don't do that, which I approve or reject. From there I write a synopsis, [...] and if they approve it, I go [produce it]. Then I publish it... It's usually a really quick process... 
It's quite a procedure to talk about what's okay and what's not and they [United Screens] do it for you, then when it's done, they contact you. (Respondent H)

This section has highlighted the key components of United Screens' value propositions to advertisers and content creators. We next turn to exploring the configurations of the collaborative projects managed by United Screens, and the organizational structures that United Screens has put in place to organize work internally.

\subsection{Organizational form}

United Screens' operations are organized in five business divisions; sales, partner management, project management, production and rights management. The sales team handles an array of activities related to advertisers and content creators. It is responsible for finding new clients, dealing with incoming requests, and taking care of established collaborations. When United Screens was first established, it focused on selling complete concepts, however organizational members soon realized that this was not an optimal strategy. Instead, they started to fully tailor their approach to suit each client's needs, desires and goals.

Most of the sales team's activities involve reaching out to prospective customers and educating them about the benefits of online video marketing. Firms are slowly realizing that broadcast TV commercials are no longer as effective as they were, and that new digital channels are available for distributing video content containing commercial messages. While United Screens state that they do not have a formal strategy for identifying and acquiring new customers, Respondent B argues that certain organizational traits provide a good starting point:

We try to find advertisers that we feel like, believe in YouTube, so to speak. I mean, firms who get it, and that's like, necessary. Everyone we work with once dared to take the leap, so the firms we do business with are maybe a bit braver than others. (Respondent B)

While sales efforts were initially focused on encouraging firms to try online video marketing, now they are mainly focused on matching incoming requests with potential partners:

The normal procedure is that we receive a brief, and then based on that brief, we look [for example] for someone [a partner] that reaches 15-25 year old females who could be interested in this, then we present these proposals. (Respondent E).

Similarly, if there is an idea about a concept that a partner would like to do, the task is to match that concept with a suitable customer.

The partner management team is also involved in managing affiliations. However, according to
Respondent D, growing the number of partners is currently not prioritized. Rather, United Screens are highly selective, requiring partners to be dedicated and motivated:

We don't work with anyone. We have to see some sort of potential, but... even if a [content creator] has 100 subscribers, and another 10 000, we may still see potential in the one with 100 [subscribers]. Clearly, persistent content creators, who keep making videos, are the ones who eventually make it big (Respondent B)

Although United Screens work with relatively few selected partners they want to attract diverse crowds of viewers. Therefore, they cover genres including food, music, beauty, gaming, fitness, and parenting:

Working with selected partners allows us to widen our reach, in terms of both interests and ages covered [...] when YouTube was launched, everyone thought it was only about cats on skateboards and shit like that. We work really hard with promoting high-quality content on YouTube, not only for ages 15-20. (Respondent C)

All of United Screens' partners have their own partner managers who help them with everything from choosing the best thumbnail for a video to coordinating branded content collaborations. The partner managers are also involved in matching incoming collaboration requests from advertisers with content creators that fit the genre. Essentially, a partner manager's responsibilities are focused on helping partners to optimize their channels and to act in their best interests.

The partner management team is tied to the sales division by the project management team, which thus mediates interactions between customers and partners, and is responsible for ensuring that each collaboration meets the expectations of all actors involved:

The key objective of our project managers is to make a great deal. That means catering to the needs of both partners and advertisers. It's important that neither us partner managers nor the sales team interferes in this process. Project managers should be fully neutral, and look for the best combinations. (Respondent D)

While the production team is involved in cases where customers and partners need assistance in the actual making of a video, the project management team can play a significant operative role in certain collaborations. For example, they handle questions or disagreements regarding the tone and language to be used in a specific context:

The level of involvement of the project management team varies. Sometimes we play a smaller part, other times we play a huge one. The same goes for the production team; sometimes they film, edit, deal with 
audio and lights and everything like that. It differs a lot: It's impossible to say that we play a singular roleit's always different. (Respondent D)

Finally, the rights management team can be extensively involved if campaigns require intense copyright-related work.

Our respondents highlight that the relationships between United Screens' divisions are fluid, constantly changing to fit their dynamic context. Several respondents stress that everyone at United Screens does a bit of everything, and there is a notable absence of formal specifications of the firm's routines and processes. Respondent E explains:

It's not like McDonald's. We don't have one person cooking the fries, another one handling checkout, and a third one doing something else. We continuously learn how things can be done.

This section has examined United Screens' organizational form and highlighted the various forms of roles it takes in managing collaborative projects involving advertisers and content creators. We next turn to exploring emergent tensions related to control over digital content.

\subsection{Dispersion of control}

Historically, firms controlled most elements involved in their marketing efforts. However, the emergence of digital platforms and social media networks is dramatically transforming the nature of advertising. At Unites Screens, active branded content collaborations can be challenging for advertisers, because they must relinquish some of the control they have previously exercised over portrayal of their brands. Our respondents at United Screens argue that the key issue for their customers in this transformation is to realize that they need to let the content creators take control of the creative process:

A lot of customers want to be involved during the whole process - but they have to realize that there is no way that they can control the influencer. If a customer hands me a manuscript specifying what the influencer should say, I will tell them that we simply don't work that way. They're starting to understand this, but still, marketing managers are scared since they are used to deciding everything themselves. (Respondent E)

What we're after is organic reach: an organic fit with the viewer [...] To achieve that, video clips have to be authentic. The customer has to allow our partners to do it the way they want to. Otherwise it won't work. What we do is try and make our customers understand that this relationship is fundamental - you can record a traditional [broadcast TV] video commercial with a YouTuber [...] but it won't have the same effect. (Respondent $\mathrm{C}$ )

Because their followers know their style and tone, it is essential that content creators stay true to themselves. One respondent described that if YouTubers spoke of new brands every day, or (for example) promoted hamburgers despite being vegans, they would lose credibility, and consequently their followers.

We can't have some posh PR-agency telling Sp4zie [one of United Screens' biggest YouTubers] what to say or do in his videos. They don't know his audience, and they don't know his tone. They know nothing so they shouldn't be there. They can be creative around a lot of stuff, but not around his content and his channel... all of our partners who have become successful... there's nothing as important as their viewers; they'd never do anything to upset them. (Respondent E)

The YouTubers interviewed say that this can be frustrating for advertisers at times, but advertisers usually understand when they are presented with the arguments:

At first they object, but then we explain to them, and they have to understand that we are experts on our platform. (Respondent G).

Concerning Unites Screens' share of control, Respondent A describes it as simultaneously large and small. Regarding their involvement in forming concepts in terms of numbers of videos, profiles, themes and lines of argument, they do control some aspects of a campaign, but not as much as partners and advertisers:

We make sure everything works, what we actually control is the beginning of a campaign where we match brands with content creators. Regarding content, we can come up with ideas but it always boils down to what the two actors want to do and achieve. (Respondent F)

Online video can be said to challenge some of the hierarchical structures associated with the broadcast TV industry, as anyone with a smartphone and an Internet connection can produce content and publish it on online video platforms and networks such as YouTube:

In [broadcast] $T V$, there is always a program director deciding what people should watch at $8 \mathrm{pm}$ on Thursdays [...] Two years ago, I met a production firm saying that "30 minutes of recorded material costs half a million [Swedish crowns], everyone knows that, that's standard". Well yeah, but Sp4zie records with his webcam and reaches more viewers than your entire season of Let's Dance [Swedish version of Strictly come dancing/Dancing with the stars]... He doesn't need you to reach out with his material; an artist 
doesn't need a record label. Previously you needed a record label to sell records on the other side of the globe; you needed one to print your CDs and you needed one to transport your CDs by some tired truck, through the smog and out to a shop that has someone who sells stuff and pays the rent. That's not necessary today; I upload my video or my song through a mouse click, and if it's good enough there's nothing saying that I can't reach 20 million streams. (Respondent E)

In an environment where access to content and decision-making is highly distributed, firms are challenged to adapt to shifting power relations. Against this backdrop, Respondent $\mathrm{E}$ argues that the key reason for United Screens' success in growing a business is that they are a recent, digital startup:

Because we are a small and young firm, we have been able to view things differently than [traditional] record labels and TV [broadcasting networks]. We have been able to build an organization based on new conditions, where content creators have a reach of their own. All actors that work with this have to adjust their splits and business models according to this new reality. But that's tough for a TV-broadcasting network with a 4.5 billion [Swedish crowns] turnover. It's not about the big eating the small - it's the fast eating the slow. We have built a completely different kind of organization that is much more beneficial for content creators and that's our advantage.

As illustrated by the above quote, agility and adaptability are key aspects of United Screens' business. Rather than formulating detailed strategies or designing advanced organizational configurations, their focus is to remain open towards dynamic conditions and relationships. Accordingly, they currently focus on YouTube, because it is the most prominent platform in terms of reach, rights and monetization. However, several respondents emphasize that United Screens' ambition is to be present where their partners are, or would want to be, so their engagement with other platforms is likely to rise as competition increases.

\section{Discussion}

In this paper, we presented a case study of United Screens, which is classified as an MCN, a recently emerging actor category that operates in the digital video-sharing ecosystem. In so doing, we explored key aspects of the logic whereby United Screens, its partners, and clients, organize to co-create value. In what follows, we discuss the contributions and implications of the study.

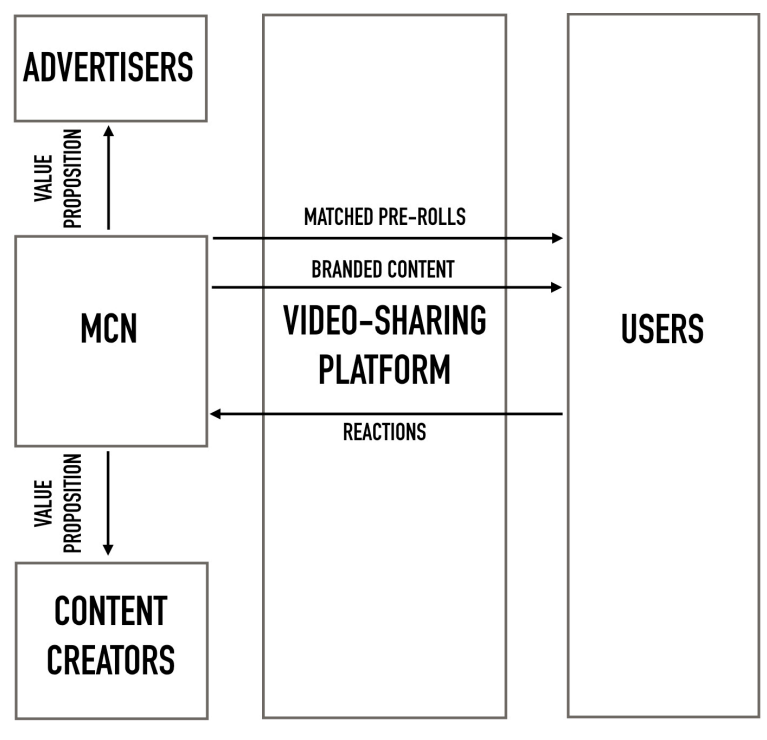

\section{Figure 1. United Screens' value constellation and platform ecosystem relationships}

Figure 1 illustrates the value constellation formed by United Screens and their partners, as well as the relationships between the aforementioned actors and the video-sharing platform (in this case YouTube), and its users. As illustrated in the model, United Screens articulate value propositions to both advertisers and content creators. Firstly, the components of United Screens' value proposition to advertisers include ensuring that mismatches between pre-rolls and clips are avoided; finding appropriate content creators for branded content collaborations, delivering directed and targeted exposure of the advertisers' brands or products, and the capture and interpretation of analytic data on usage patterns and user interactions. Secondly, the components of United Screens' value proposition to content creators include studio facilities, channel development, audience growth, audio and visual rights management, administrative support, and training services.

Our findings show how a key responsibility for United Screens is to manage advertisers' and content creators' respective desire to exercise control over content during production. While doing so remains a challenge, the case also reveals how individual content creators are starting to be recognized as important players in the market. Notably, our respondents highlighted that advertisers are gradually taking a step back, acknowledging the expertise of content creators and platform specialists, confirming previous claims that digital product architectures can trigger shifts in positions of new and established actors [cf. 30]. 
While there are various video-sharing platforms available on the market, like most other MCNs, United Screens predominantly utilizes YouTube as its main content distribution channel for its matched pre-rolls and branded content (see Figure 1). Largely building a business on the YouTube platform has enabled United Screens to enjoy a relatively large degree of freedom, while operating in a well-established environment that is fairly stable [cf. 1, 8]. Still, when reflecting on the distribution of control among the actors in Figure 1, the fact remains that YouTube exercises relatively full control over the service-layer. Having successfully cultivated a multi-sided market, one of YouTube's key assets is their digital video library that is rapidly growing as new contents are constantly uploaded. Still, in relation to major content creators and MCNs, it is reasonable to assume that YouTube is constantly challenged to balance control and openness of its platform [cf. 9, 5]. Therefore, MCNs such as United Screens are vulnerable in that any platform changes may directly threat the viability of their current value propositions to advertisers and content creators.

In contrast to broadcast TV's relatively passive mass audiences, video-sharing platform users are able to actively engage with contents through reacting (see Figure 1) to clips by commenting, discussing, or liking them. In this way, users both interact among each other, and occasionally directly with the content creator. In this way, users co-create value at the point of use [cf. 31] as they make active decisions about which content to view and when, and whether or not to engage with it through the social features offered by the particular video-sharing platform. Further, in contrast to the tightly coupled layers of traditional broadcast TV, the digital product architectures of video-sharing platforms allow users to control what devices and networks they want to utilize in consuming and interacting with contents and services. Not the least, video-sharing platform users can at any point decide to become content creators themselves.

Our research adds to the emerging body of digital innovation research that investigates the organization of value co-creation in digital platform ecosystems. Given the predominant focus on the role of apps and third-party development as a driver of innovation in the service layer and the logical dimension of the device layer [5, 9], our study significantly contributes by generating rich insight on value co-creation based on digital contents - an understudied aspect in digital innovation research. Further, as noted by Selander et al [25], scholars tend to focus on platform owners as focal units. We contribute to complementing such a perspective by shedding some new light on the dynamics of value co-creation in digital platform ecosystems through centering our investigation on a novel actor category that has emerged as a consequence of the rise of YouTube as a powerful digital platform. However, the implications of our findings also have several limitations. Our analysis draws on a case study of a single organization and therefore we do not claim that our findings can be generalized to larger populations. Further, our findings in essence provide a snapshot of value co-creation practices involving digital content at an $\mathrm{MCN}$. Given the nature of digital platform ecosystem dynamics, we encourage process-oriented studies that address the evolution of such practices over time.

Our findings call for new ways to describe and conceptualize business strategies that are apposite for emerging actor categories in the digital domain. Here, we specifically encourage future research to investigate the role of individual content creators - a group that is constantly increasing and gaining power in the digital media ecosystem. This paper has only just begun to establish an understanding of MCNs. To fully comprehend the sociotechnical mesh of processes shaping how new actors create value in the digital era, we also encourage more research on both MCNs and other novel actors that capitalize from various types of digital content (e.g. music, photos and texts).

\section{References}

[1] C. Y. Baldwin and C. J. Woodard, The Architecture of Platforms: A Unified View, in A. Gawer, ed., Platforms, Markets and Innovation, Edward Elgar, Cheltenham, UK, 2011, pp. 19-44.

[2] A. Bryman, Quantity and Quality in Social Research, Routledge, New York, NY, 2003.

[3] M. Burke, R. Kraut and C. Marlow, Social Capital on Facebook: Differentiating Uses and Users, Proceedings of the SIGCHI Conference on Human Factors in Computing Systems, ACM, Vancouver, BC, Canada, 2011, pp. 571-580.

[4] Deloitte, "Digital Democracy Survey: A MultiGenerational View of Consumer Technology, Media and Telecom Trends", 2015. Retrieved March 19, 2016, from https://www2.deloitte.com/content/dam/Deloitte/global/Docu ments/Technology-Media-Telecommunications/gx-tmt-

deloitte-democracy-survey.pdf

[5] B. Eaton, S. Elaluf-Calderwood, C. Sørensen and Y. Yoo, "Distributed Tuning of Boundary Resources: The Case of Apple's iOS Service System", MIS Quarterly, 39(1), 2015, pp. 217-243.

[6] Ericsson, "Tv and Media 2015: The Empowered Tv and Media Consumer's Influence", 2015. Retrieved April 2, 2016, from http://www.ericsson.com/res/docs/2015/consumerlab/ericsso n-consumerlab-tv-media-2015.pdf

[7] R. Garud, S. Jain and P. Tuertscher, "Incomplete by Design and Designing for Incompleteness", Organization Studies, 29(3), 2008, pp. 351-371. 
[8] A. Gawer, "Bridging Differing Perspectives on Technological Platforms: Toward an Integrative Framework", Research Policy, 43(7), 2014, pp. 1239-1249.

[9] A. Ghazawneh and O. Henfridsson, "Balancing Platform Control and External Contribution in Third-Party Development: The Boundary Resources Model", Information Systems Journal, 23(2), 2013, pp. 173-192.

[10] K.-Y. Goh, C.-S. Heng and Z. Lin, "Social Media Brand Community and Consumer Behavior: Quantifying the Relative Impact of User- and Marketer-Generated Content", Information Systems Research, 24(1), 2013, pp. 88-107.

[11] Google, "Multi-Channel Network (Mcn) Overview", n.d. Retrieved April 4, 2016, from https://support.google.com/youtube/answer/2737059

[12] V. Grover and R. Kohli, "Cocreating IT Value: New Capabilities and Metrics for Multifirm Environments", MIS Quarterly, 36(1), 2012, pp. 225-232.

[13] A. Hagiu and J. Wright, "Multi-Sided Platforms", International Journal of Industrial Organization, 43, 2015, pp. 162-174.

[14] O. Hanseth and K. Lyytinen, "Design Theory for Dynamic Complexity in Information Infrastructures: The Case of Building Internet", Journal of Information Technology, 25(1), 2010, pp. 1-19.

[15] L. Kozlowski, "Multi-Channel Networks 101", Forbes, 2013. Forbes. Retrieved April 4, 2016, from http://www.forbes.com/sites/lorikozlowski/2013/08/30/multichannel-networks-101/\#557a766d6fa6

[16] R. F. Lusch and S. Nambisan, "Service Innovation: A Service-Dominant Logic Perspective", MIS Quarterly, 39(1), 2015, pp. 155-176.

[17] M. B. Miles, A. M. Huberman and J. Saldana, Qualitative Data Analysis: A Methods Sourcebook (3rd Ed.), Sage Publications, Thousand Oaks, CA, 2013.

[18] R. Normann and R. Ramirez, "From Value Chain to Value Constellation: Designing Interactive Strategy", Harvard Business Review, 71(4), 1993, pp. 65-77.

[19] M. Pagani, "Digital Business Strategy and Value Creation: Framing the Dynamic Cycle of Control Points", MIS Quarterly, 37(2), 2013, pp. 617-632.

[20] M. Parameswaran and A. B. Whinston, "Research Issues in Social Computing", Journal of the Association for Information Systems, 8(6), 2007, pp. 336-350.

[21] M. E. Porter, Competitive Advantage: Creating and Sustaining Superior Performance, Free Press, New York, NY, 1985.

[22] J. Ritchie and J. Lewis, Qualitative Research Practice: A Guide for Social Science Students and Researchers, Sage Publications, London, UK, 2003.

[23] V. Sambamurthy and R. W. Zmud, "Research Commentary: The Organizing Logic for an Enterprise's IT
Activities in the Digital Era - a Prognosis of Practice and a Call for Research", Information Systems Research, 11(2), 2000, pp. 105-114.

[24] S. Sarker, X. Xiao and T. Beaulieu, "Qualitative Studies in Information Systems: A Critical Review and Some Guiding Principles", MIS Quarterly, 37(4), 2013, pp. iii-xviii. [25] L. Selander, O. Henfridsson and F. Svahn, "Capability Search and Redeem across Digital Ecosystems", Journal of Information Technology, 28(3), 2013, pp. 183-197.

[26] Socialbakers, "Pewdiepie Youtube Channel Statistics", n.d. Retrieved April 2, 2016, from http://www.socialbakers.com/statistics/youtube/channels/deta il/UC-1HJZR3Gqxm24_Vd AJ5Yw-pewdiepie

[27] A. Susarla, O. Jeong-Ha and T. Yong, "Social Networks and the Diffusion of User-Generated Content: Evidence from Youtube", Information Systems Research, 23(1), 2012, pp. 23-41.

[28] D. Tilson, K. Lyytinen and C. Sørensen, "Research Commentary-Digital Infrastructures: The Missing IS Research Agenda", Information Systems Research, 21(4), 2010, pp. 748-759.

[29] A. Tiwana, B. Konsynski and A. A. Bush, "Research Commentary-Platform Evolution: Coevolution of Platform Architecture, Governance, and Environmental Dynamics", Information Systems Research, 21(4), 2010, pp. 675-687.

[30] E. Vaast, E. J. Davidson and T. Mattson, "Talking About Technology: The Emergence of a New Actor Category through New Media", MIS Quarterly, 37(4), 2013, pp. 10691092.

[31] S. L. Vargo and R. F. Lusch, "Evolving to a New Dominant Logic for Marketing", Journal of Marketing, 68(1), 2004, pp. 1-17.

[32] C. Vollmer, S. Blum and K. Bennin, "The Rise of Multichannel Networks: Critical Capabilities for the New Digital Video Ecosystem", PWC, 2014. Retrieved April 4, 2016, from http://www.strategyand.pwc.com/media/file/Therise-of-multichannel-networks.pdf

[33] R. K. Yin, Case Study Research: Design and Methods, Sage Publications, Thousand Oaks, CA, 2003.

[34] Y. Yoo, Digital Materiality and the Emergence of an Evolutionary Science of the Artificial, in P. M. Leonardi, B. A. Nardi and J. Kallinikos, eds., Materiality and Organizing: Social Interaction in a Technological World, Oxford University Press, Oxford, UK, 2012, pp. 134-154.

[35] Y. Yoo, O. Henfridsson and K. Lyytinen, "Research Commentary-the New Organizing Logic of Digital Innovation: An Agenda for Information Systems Research", Information Systems Research, 21(4), 2010, pp. 724-735.

[36] J. Zittrain, The Future of the Internet--and How to Stop It, Yale University Press, New Haven, CT, 2008. 